\title{
The effects of an empowering self-management model on self-efficacy and sense of coherence among retired elderly with chronic diseases: a randomized controlled trial
}

This article was published in the following Dove Press journal:

Clinical Interventions in Aging

\author{
Azam Hourzad' \\ Shahnaz Pouladi ${ }^{2}$ \\ Afshin Ostovar ${ }^{3}$ \\ Maryam Ravanipour ${ }^{4}$ \\ 'Department of Nursing, School \\ of Nursing and Midwifery, Bushehr \\ University of Medical Sciences, \\ Bushehr, Iran; ${ }^{2}$ Department of Nursing, \\ School of Nursing and Midwifery, \\ Bushehr University of Medical \\ Sciences, Bushehr, Iran; ${ }^{3}$ Osteoporosis \\ Research Center, Endocrinology \\ and Metabolism Clinical Sciences \\ Institute, Tehran University of Medical \\ Sciences, Tehran, Iran; ${ }^{4}$ Department \\ of Nursing, School of Nursing and \\ Midwifery; and The Persian Gulf \\ Tropical Medicine Research Center, \\ The Persian Gulf Biomedical Sciences \\ Research Institute, Bushehr University \\ of Medical Sciences, Bushehr, Iran
}

Background: Being elderly and retired are related phenomena that overlap in a time symmetry. The present study aimed to assess the effect of an empowering self-management model on the self-efficacy and sense of coherence (SOC) in retired elderly with chronic diseases.

Methods: A randomized controlled trial that included 60 elderly people was carried out in Bushehr (Iran) in 2016. The participants were randomly assigned to either a control group or an intervention group. Based on an empowering self-management model, the intervention group participated in a five-stage plan: 1) self-awareness of changes and understanding their personal level of performance and expectations; 2) optimal goal setting; 3) planning; 4) adjusting physical, psychological, and social structures; and 5) evaluation. Self-efficacy and SOC were measured using the questionnaires developed by Sherer and Antonovsky, respectively, before and after the intervention. The results of the observed differences between the groups were subsequently compared. Data were presented as mean \pm SD.

Results: The mean change of the self-efficacy score in the intervention and control groups was $9.48 \pm 5.32$ and $1.68 \pm 6.04$, respectively, $(\mathrm{t}[56]=5.20, P<0.001)$. The mean change of the SOC score in the intervention and control groups was $24.17 \pm 12.05$ and $0.10 \pm 13.42$, respectively, (t[56] $=7.18, P<0.001)$.

Conclusion: The applied empowering self-management model led to an improved self-efficacy and SOC among the retired elderly with chronic diseases. This model can be used to empower the elderly to achieve comprehensibility, manageability, and meaningfulness in their lives.

Keywords: empowerment, chronic diseases, retirement, self-efficacy, sense of coherence, aging

\section{Introduction}

The increasing number of older population is the most challenging issue to the health and well-being of a society. ${ }^{1}$ Currently, in USA, people aged 65 years and older represent more than $12 \%$ of the total population, and it is projected that this group will increase to $20 \%$ by $2030 .^{2}$ In Iran, the population aged over 60 years is projected to reach 8.5 million by 2020 and 10.5 million by $2025 .^{3}$ Population aging occurs both in the developed and developing countries; however, the growth rate is fastest in the developing countries. The impact and challenges of the aging population have already been felt in Iran. ${ }^{4}$ Exacerbating the matter is the fact that many of the Iranian parents have a cultural tendency to spend their savings on their children (eg, education, property, and wedding expenses). Consequently, in the absence of social security, they will face financial problems at an older age trying to address their health costs. ${ }^{5}$
Correspondence: Maryam Ravanipour Department of Nursing, School of Nursing and Midwifery, Bushehr University of Medical Sciences, Rishehr Street, PO Box 7518759577, Bushehr, Iran

Tel +98 7733450187

Fax +987733450187

Email ravanipour@gmail.com 
Being elderly and retired are related phenomena that overlap in a time symmetry with consequences such as loneliness, social isolation, and financial problems. ${ }^{6,7}$ These factors may lead to feelings of ineffectiveness, helplessness, and powerlessness. An additional consequence is a physical and psychological dependency on family members, ${ }^{8}$ which in turn negatively affects their quality of life (QoL). ${ }^{9}$ It is shown that the elderly still have the capacity for flexibility and adaptation. ${ }^{10}$ Hence, effective interventions would be beneficial to their intellectual, psychological, social, and spiritual empowerment. ${ }^{11,12}$

Self-efficacy, a psychological factor rooted in Bandura's cognitive theory, ${ }^{13}$ is an important cognitive function of a person. The term is defined as the sense of responsibility of each person toward a part of their personal health status, the ability to understand the conditions and factors related to themselves, and an optimal control over the surrounding environment. ${ }^{14-16}$ Self-efficacy plays a significant role in improving one's general health and dealing with chronic diseases ${ }^{17}$ and is closely related to demographic and social characteristics. ${ }^{16}$ Higher self-efficacy leads to a more effective response to fatigue and stressful events, greater life satisfaction, more dynamic physical performance, and a significant improvement in daily activities and self-care. ${ }^{17,18}$

The sense of coherence (SOC), introduced by Antonovsky, is a personal orientation that emphasizes on stress management through three basic concepts: comprehensibility (cognitive component), meaningfulness (motivational component), and manageability of events (instrumental component). ${ }^{19-21}$ SOC is an important concept of Antosovsky's theoretical model of salutogenesis. The aim of the salutogenic approach is to explain how people remain healthy rather than how people become ill. ${ }^{21}$ The salutogenic theory suggests that people have access to various resources to resist and cope with stress-producing experiences. Individuals who frequently resort to such resources during their developmental phase have a higher SOC. ${ }^{21}$ During the last decade, many studies have applied the salutogenic approach to healthy aging people. ${ }^{22}$ SOC has also a high correlation with health factors in the field of psychology and disease. ${ }^{23,24}$ People with higher SOC have a better QoL, ${ }^{25}$ improved physical health, and a higher level of well-being. ${ }^{26}$ Another prominent concept related to SOC is self-efficacy. ${ }^{22}$ SOC and self-efficacy are very much related concepts. The findings of a study gave further evidence for the construct validity of self-efficacy and SOC, suggesting that they are highly related constructs. ${ }^{27}$ Another study recommended further research among different age groups and social contexts to identify the potential benefits of exploratory synthesis and theoretical development of these two major health concepts. ${ }^{28}$

According to the elements of the salutogenic theory, personal empowerment can be defined as a process in which people gain control over their lives, learn to find a closer link between goals and efforts, and find ways to set goals and achieve results. ${ }^{29}$ The use of empowerment models as a process and an outcome, introduced by Paolo Freire in 1970, ${ }^{30}$ can improve self-efficacy and SOC. It can lead to improved conditions for the elderly to manage aging problems. Empowerment has been used in different studies with the aim of achieving self-sufficiency, ${ }^{31}$ which includes increasing self-control of individuals, ${ }^{32}$ changing the attitude of a patient toward disease and encompassing its course, ${ }^{11}$ and the ability of self-care and satisfaction..$^{33}$ Since 1989 , the concept of empowerment has been generally proposed for the care of diabetic patients ${ }^{34}$ and has gradually become a noble and familiar concept in nursing literature. ${ }^{35}$ Applying a theoretical framework to implement empowerment interventions can help researchers to build on different concepts of empowerment, which will have better effects than interventions without an underlying theory. ${ }^{24}$ Ravanipour et al developed an empowering self-management model following a study on the concept of "power" among a sample of Iranian older adults. The model included basic structures to understand the concept of "power" among the elderly (eg, awareness of changes, autonomy, role performance, adaptation, assumed satisfaction, sense of control, and self-management). ${ }^{33}$

To the best of our knowledge, there are no studies assessing the effect of an empowering self-management model on the self-efficacy and SOC among the retired elderly people. Hence, the present study was designed to evaluate the effectiveness of an empowering self-management model on the self-efficacy and SOC in the retired elderly with chronic diseases.

\section{Methods}

\section{Research population and sample size}

The participants of the present randomized controlled trial were retired elderly living in a dwelling in Bushehr (Iran) with at least one officially diagnosed chronic disease. According to the Iranian Ministry of Health and Medical Education, in 2011, the most common types of chronic diseases in Iran were diabetes mellitus, hypertension, and coronary artery disease. ${ }^{36,37}$ The inclusion criteria were aged $\geq 60$ years, at least one officially diagnosed chronic disease (ie, diabetes mellitus, hypertension, and coronary artery diseases), have received medical treatment and related recommendations on lifestyle changes prescribed by a doctor for a minimum 
of 1 year, officially retired and receiving a pension, literate (Persian language), and provided written informed consent to participate in the research. The exclusion criteria were the presence of officially diagnosed psychological disorders (eg, schizophrenia, depression, and anxiety disorders), consumption of any psychiatric drugs that affect thoughts and behavior (ie, antipsychotics, antidepressants, and benzodiazepines), participation in parallel studies, and relocation to other cities.

The sample size was calculated using the Gpower software, version 3.1.9. Based on the difference in the mean SOC score of 20 and 12 in the intervention and control groups, respectively, the estimated sample size was 26 participants. The assumed SD was 10 in both groups, ${ }^{38}$ and the statistical power of $80 \%$ and alpha of 0.05 were chosen. Assuming a $20 \%$ loss to follow-up, we decided to allocate 30 individuals to each group. Based on the convenient sampling, the participants were selected among those referred to the public health care center in Bushehr (the only center that provides an elderly health care program). In accordance with the permuted block randomization method (block size of 4), those who met the inclusion criteria were allocated to the control and intervention groups.

\section{Empowering self-management intervention}

The participants in the intervention group received an empowerment program based on an empowering self-management model ${ }^{33,39}$ Initially, the participants in both groups completed a demographic information form and Sherer's self-efficacy and Antonovsky's SOC questionnaires. The participants in the control group received routine care from the health care center that included screening tests performed by health care team for common diseases (diabetes mellitus, hypertension, and coronary artery diseases), annual visits by a general physician, referral to a specialist in case of complications, and a group training on general healthy lifestyle (not on an individual basis). Two months later, the participants completed the questionnaires again. Based on the empowering self-management model, the intervention group participated in a five-stage plan over a 2-month period. The stages were as follows: 1) self-awareness of changes and understanding their personal level of performance and expectations; 2) optimal goal setting; 3) planning; 4) adjusting physical, psychological, and social structures; and 5) evaluation.

The content of the intervention was determined based on a literature review and the findings of a qualitative study that enhanced the perception of "power" among a sample of Iranian older adults. ${ }^{39}$ To homogenize the intervention, an algorithm was developed based on the steps and the content of an empowerment model of self-efficacy and SOC. The model was developed based on the expert opinions of nurses and public health care professionals, which included a set of specific objectives and goals. Several "at least" measures were identified in the algorithm to ensure the quality of the intervention. If a participant did not execute $\geq 40 \%$ of the specified items in the algorithm, that person was excluded from the study.

\section{Stage I: self-awareness of changes and understanding personal level of performance and expectations}

In this stage, a face-to-face interview with the retired elderly was conducted using the evaluation forms (based on the empowering self-management model) and a dedicated algorithm. The assessment forms were used to evaluate the elderly's awareness level on the extent of changes in their physical, mental, and social abilities (particularly after retirement). Based on their lifestyle and living environment, the status of their performance, autonomy, adaptation to the existing conditions, support resources, and expectation level was assessed. Subsequently, their current expected level of performance was determined with respect to the predefined limits (proportional/inappropriate, excessive/less).

\section{Stage 2: optimal goal setting}

In this stage, together with the participants, a set of goals was defined in line with the evaluation of the previous stage and based on their health assessment and current range of problems. The participants were assisted in setting optimal goals by identifying the available supporting resources and the possibilities for changing or modifying those resources toward the development of a set of strategies. These strategies would benefit the elderly in terms of health improvement, enhancement of preventive behaviors, higher self-esteem leading to improved self-care behaviors, more compliance with the long-term use of medication, a better understanding of changes (physical, mental, and social abilities), and enhanced ability to manage stressful events.

To ensure uniformity and consistency of the data, only one researcher (the first author) was involved in the interventions. The information from this stage was registered on the prescribed forms and prioritized together with the participants.

\section{Stage 3: planning}

In this stage, based on the developed goals, a plan was drawn to improve the self-efficacy and SOC of the participants. The plan incorporated the recommendations of the participants, 
available resources, and our expertise in the empowerment model.

Note that the first three stages of the intervention (assessment, goal setting, and planning) were performed in two 45-minute sessions.

\section{Stage 4: adjusting physical, psychological, and social structures}

In this stage, the participants were requested to implement the defined empowering self-management strategies, as well as drawn up plan, based on their health status and available resources. Several examples for such implementation were given, for instance, empowering them to receive timely information from the medical team on various aspects of their disease, to learn new skills to compensate for their shortcomings, to learn how to handle available resources to maintain their health, to gain new empowerment skills (eg, pottery, fishing, work in a bookstore, gardening), to participate in religious ceremonies, to preserve their role in the family, and to communicate effectively with those around them. In support of the implementation phase, the participants in the intervention group were provided with an educational booklet (book and papers). These were written in a clear and simple language and in line with the main objectives and criteria of the intervention (eg, solutions to tackle problems, social support, and stress management skills to follow-up with home education). Since some of the participants were less educated, a family member or friend was asked to read out the educational booklet and emphasize on the actions regarding implementations and appropriate skills. The intervention sessions during stages 1-3 lasted 2 weeks. The participants were then requested to implement the defined strategies (stage 4) within 6 weeks (total intervention of 8 weeks) during which the intervention team followed up their progress by phone on weekly basis. In support of the implementation phase, the participants were advised to use the educational booklet and could freely call the intervention team by phone to clarify any ambiguities or to answer questions.

\section{Stage 5: evaluation}

A follow-up evaluation was conducted over a 6-week period to ensure proper implementation of the proposed program and interventions. To evaluate the accuracy of the intervention process and the empowerment of the participants, the intervention team regularly followed up each participant separately during these 6 weeks. The follow-up was in accordance with the predefined goals after assessment of the problems and the provision of appropriate measures.
The corresponding forms were completed for each participant. Such a follow-up process was extremely useful for extracting the exact information related to the intervention process and the achieved goals. In accordance with the exclusion criteria, a participant was excluded from the study if $\geq 40 \%$ of the specified items were not executed. As mentioned earlier, the intervention group received 2 weeks of interviews and in-person trainings followed by 6 weeks of implementation (total intervention of 8 weeks). In the same timeframe, the control group only received routine care.

\section{Data collection}

The Sherer's self-efficacy and Antonovsky's SOC questionnaires together with the demographic form were used as the data collection tools. The forms were completed by the participants in both groups during the interview before the intervention (baseline) and at the end of the intervention. The demographic data included age, sex, marital status, educational level, number of family members, history of any chronic disease(s), duration of the disease(s), the degree of disease management, employment status, and retirement age.

The Sherer's self-efficacy questionnaire included 23 items, of which 17 items were related to general self-efficacy and six items were related to self-efficacy experiences. The questionnaire was scored based on a 5-point Likert scale (1=totally disagree, 5=totally agree, and 3=do not know). In this questionnaire, 11 questions were scored in a reverse order. Sherer et $\mathrm{al}^{40}$ confirmed the validity and reliability of the questionnaire (Cronbach's alpha=0.86). The reliability of the Iranian version of the questionnaire was confirmed in previous studies. ${ }^{41,42}$

SOC was assessed using the Antonovsky questionnaire ${ }^{19}$ that included 29 items to measure the dimensions of comprehensibility (11 questions), manageability (10 questions), and meaningfulness (8 questions). The questionnaire was scored based on a 7-point Likert scale and had a good validity and reliability (Cronbach's alpha=0.96). The Iranian version of the questionnaire had a good validity and reliability for intercultural use. ${ }^{43}$

\section{Ethical considerations}

Initially, the study proposal was approved after which the Code of Ethics and the Code of Clinical Trial were obtained. The study was approved by the Research Council (grant number: 5436) and the Research Ethics Committee (code: ir.bpums.rec.2015.134) of Bushehr University of Medical Sciences, Bushehr, Iran. The study protocol was registered at 
the Iranian Registry of Clinical Trials (registration number: IRCT2015090513092N9).

The goals and stages of the study, as well as the confidentiality of the information (eg, names and personal issues), were explained to the participants. Optional withdrawal at any stage of the study was permitted. A written informed consent was obtained from all participants on an optional basis. At the end of the final evaluation and on completion of the questionnaires, the participants in the control group were provided with an informative booklet. The booklet was similar to that given to the intervention group.

\section{Statistical analyses}

Statistical analyses were performed using SPSS 22.0 (IBM Corporation, Armonk, NY, USA) and STATA 13.0 (StataCorp LP, College Station, TX, USA) software packages. Continuous and categorical variables were presented as mean $\pm \mathrm{SD}$ and relative frequency (\%), respectively. Histogram, box plot, and Q-Q plot, as well as the ShapiroWilks test, were used to check the normality of continuous data. The chi-squared test was used to compare demographic variables between the two groups. To determine the effect of the interventions, differences in the score of self-efficacy and SOC results (before and after interventions) between the groups were compared using the independent sample $t$-test. The analysis of covariance (ANCOVA) was performed to examine the effect of the interventions on the dependent variables, adjusted for age, sex, and baseline values. Partial eta-squared $\left(\mathrm{n}^{2}\right)$ values were reported as the effect size. $P<0.05$ was considered as statistically significant.

\section{Results}

Among the 119 elderly who were invited to participate in this study, 60 met the inclusion criteria. The participants, $37(61.7 \%)$ men and $23(38.3 \%)$ women, were assigned to the control group $(n=30)$ and the intervention group $(n=30)$. In the course of the study, one candidate from each group withdrew participation due to relocation or unwillingness. Hence, the analysis was performed on 29 participants in each group (Figure 1).

The mean ages of the participants (mean \pm SD) in the intervention and control groups were $63.86 \pm 4.18$ and $63.97 \pm 4.46$ years, respectively. An overview of the participants' characteristics in both groups is provided in Table 1. In terms of baseline variables, there was no significant difference between the intervention and control groups $(P \geq 0.05)$.

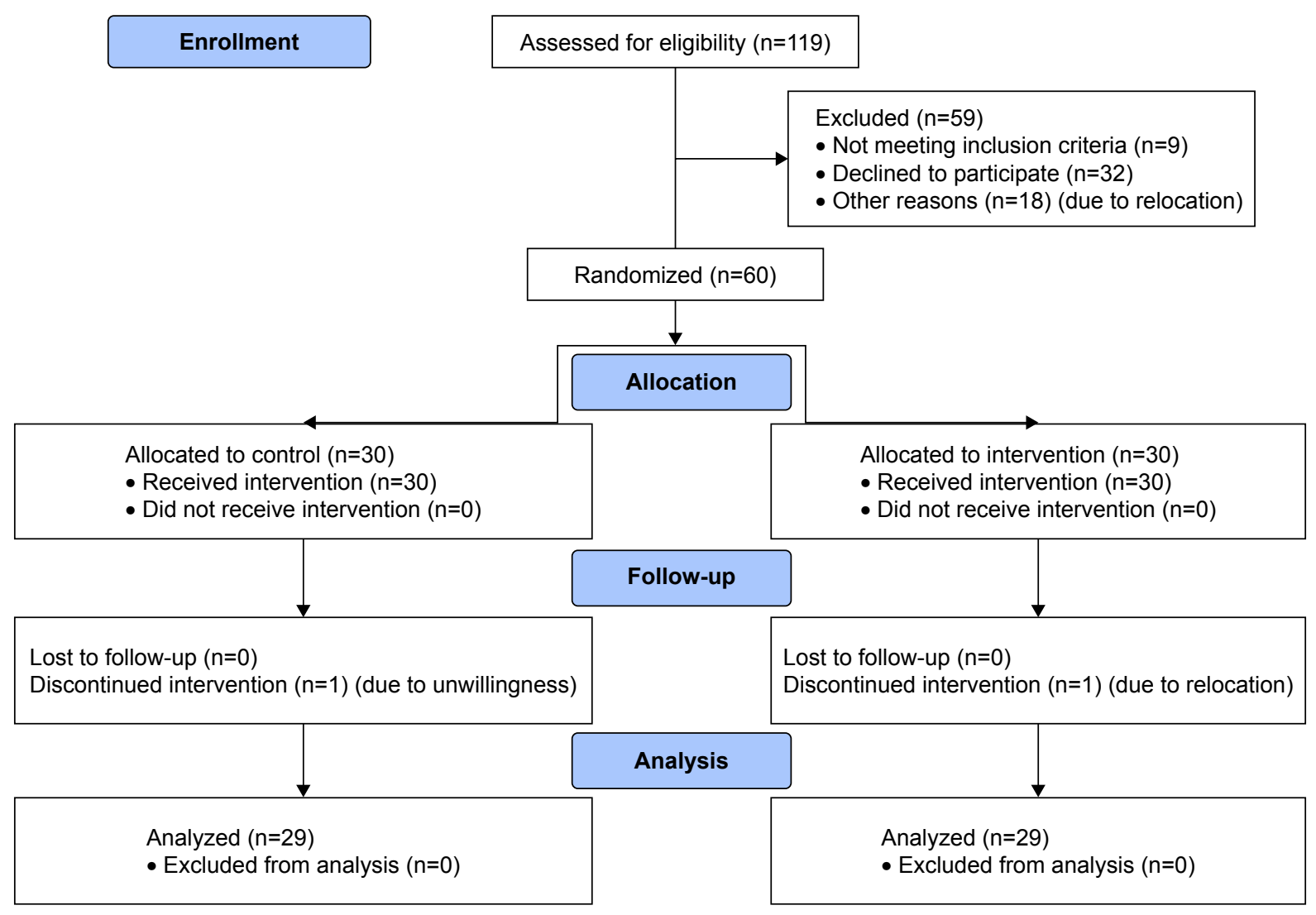

Figure I CONSORT flow diagram displaying the progress of all participants through the trial. 
Table I Characteristics and frequencies of chronic diseases among participants

\begin{tabular}{|c|c|c|c|c|c|c|c|}
\hline Variables & $\begin{array}{l}\text { Intervention } \\
(n=29)\end{array}$ & $\begin{array}{l}\text { Control } \\
(n=29)\end{array}$ & $P$-value ${ }^{a}$ & $\begin{array}{l}\text { Chronic } \\
\text { diseases }\end{array}$ & $\begin{array}{l}\text { Intervention } \\
(\mathrm{n}=29)\end{array}$ & $\begin{array}{l}\text { Control } \\
(\mathrm{n}=29)\end{array}$ & $P$-value ${ }^{a}$ \\
\hline Age & $63.86 \pm 4.18$ & $63.97 \pm 4.46$ & 0.92 & DM & $24(82.8)$ & $23(79.3)$ & 0.73 \\
\hline \multicolumn{8}{|l|}{ Sex } \\
\hline Male & $18(62.1)$ & $18(62.1)$ & 1.00 & HTN & $19(65.5)$ & $19(65.5)$ & 1.00 \\
\hline \multicolumn{8}{|l|}{ Marital status } \\
\hline Married & $28(96.6)$ & $27(93.1)$ & 0.79 & HLP & $13(44.8)$ & $15(51.7)$ & 0.59 \\
\hline \multirow[t]{2}{*}{ Widow } & I (3.4) & $2(6.9)$ & 0.30 & CAD & $5(17.2)$ & $9(3 \mathrm{I})$ & 0.22 \\
\hline & & & & $\mathrm{CHF}$ & $2(6.9)$ & 0 & 0.15 \\
\hline \multicolumn{8}{|l|}{ Companionship } \\
\hline Yes & $29(100)$ & $28(96.6)$ & 0.31 & Hypothyroidism & $2(6.9)$ & $3(10.3)$ & 0.64 \\
\hline No & 0 & I (3.4) & & Cataract & $2(6.9)$ & I (3.4) & 0.55 \\
\hline \multicolumn{8}{|l|}{ Education } \\
\hline Elementary school & $3(10.3)$ & $2(6.9)$ & 0.18 & Osteoporosis & 0 & $2(6.9)$ & 0.15 \\
\hline High school & $12(41.4)$ & $20(66.7)$ & & $\mathrm{BPH}$ & $2(6.9)$ & 0 & 0.15 \\
\hline University & $14(48.3)$ & $8(27.8)$ & & LBP & $2(6.9)$ & 0 & 0.15 \\
\hline \multicolumn{8}{|l|}{ Disease management } \\
\hline Never & $2(6.9)$ & 0 & 0.35 & & & & \\
\hline Somewhat & II (37.9) & $12(4 \mid .4)$ & & Others & I (3.4) & $4(13.8)$ & 0.31 \\
\hline Always & $16(55.2)$ & $17(58.6)$ & & & & & \\
\hline \multicolumn{8}{|l|}{ Previous training } \\
\hline Yes & $5(17.2)$ & $5(17.2)$ & 1.00 & & & & \\
\hline Baseline score SOC & $125.5 \pm 16.8$ & $130.5 \pm 22.3$ & 0.34 & & & & \\
\hline Baseline score self-efficacy & $61.1 \pm 7.3$ & $61.7 \pm 9.5$ & 0.79 & & & & \\
\hline
\end{tabular}

Notes: Data are expressed as mean \pm SD or $\mathrm{n}(\%)$. "Others" indicate rheumatoid arthritis. ${ }^{\mathrm{a}}$ The significance level was set at $P<0.05$. $P$-values provided are for the chi-square tests for the categorical, and the independent samples $t$-tests for the continuous variables.

Abbreviations: BPH, benign prostatic hyperplasia; CAD, coronary artery disease; CHF, congestive heart failure; DM, diabetes mellitus; HLP, hyperlipidemia; HTN, hypertension; LBP, low back pain; SOC, sense of coherence.

The mean self-efficacy scores increased by $9.5 \pm 5.32$ and $1.7 \pm 6.04$ in the intervention and control groups, respectively, after the intervention ( $\mathrm{t}[56]=5.20, P<0.001$; Figure 2). The ANCOVA test showed that the effect of the intervention on the self-efficacy score remained statistically significant

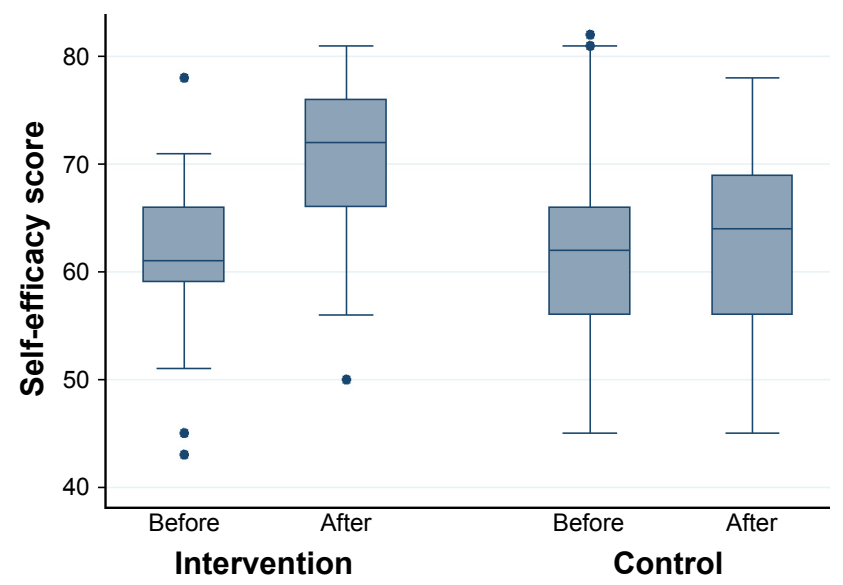

Figure 2 Box-plot diagram of self-efficacy before and after the intervention in both groups. after adjustment for potential confounders $(F[1,53]=29.8$, $P<0.001, \mathrm{nP}^{2}=0.360$ ).

After the intervention, the mean score of SOC increased by $24.2 \pm 12.05$ and $0.1 \pm 13.42$ in the intervention and control groups, respectively (t[56]=7.18, $P<0.001$; Figure 3). In addition, the mean change score of comprehensibility, meaningfulness, and manageability (the dimensions of SOC) were, respectively, $7.72 \pm 6.89,7.06 \pm 4.97$, and $9.37 \pm 7.02$ (in the intervention group); $-0.79 \pm 6.03,-0.48 \pm 6.68$, and $1.37 \pm 7.28$ (in the control group); (t [56] $=5, P<0.001$ ), (t[56] $=4.87, P<0.001)$, and (t[56]=4.25, $P<0.001$; Figure 3 ). The ANCOVA test showed that the effect of the intervention on the SOC score remained statistically significant after adjustment for potential confounders $(\mathrm{F}[1,53]=52.2$, $P<0.001, \mathrm{nP}^{2}=0.496$ ).

\section{Discussion}

The present study was conducted to assess the effect of an empowering self-management model on the self-efficacy and SOC in retired elderly with chronic disease(s) in Bushehr(Iran). 
A

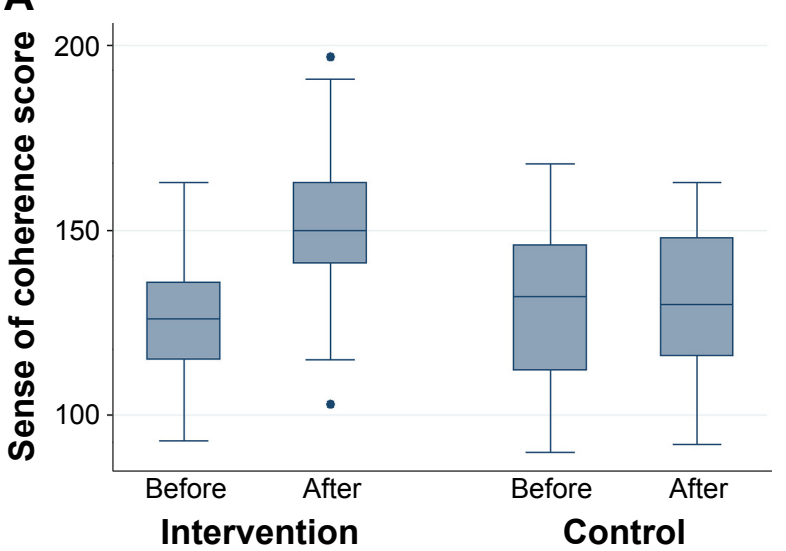

C

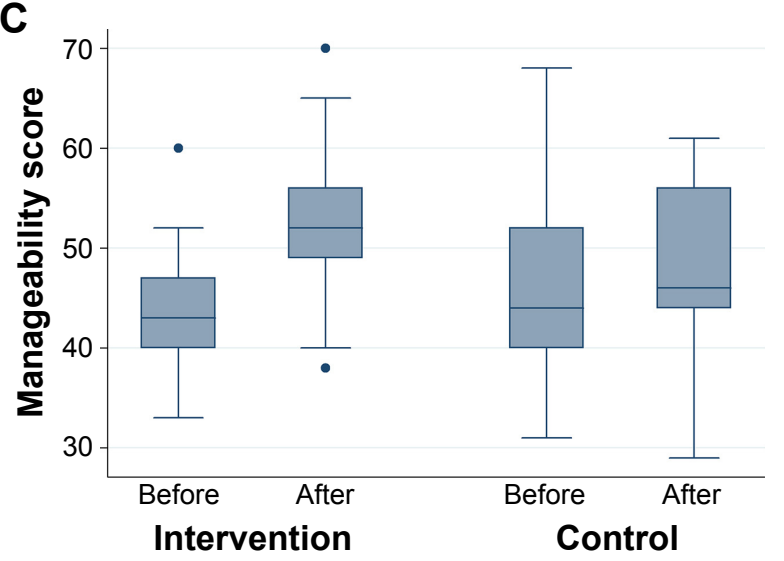

B

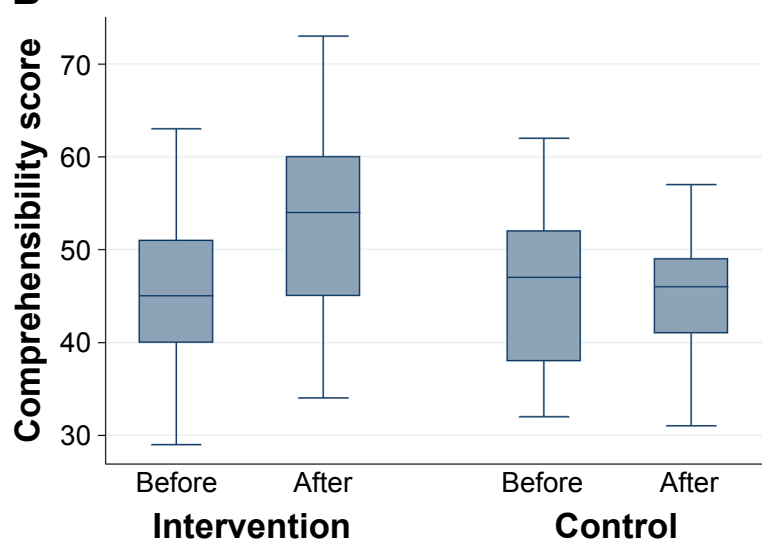

D

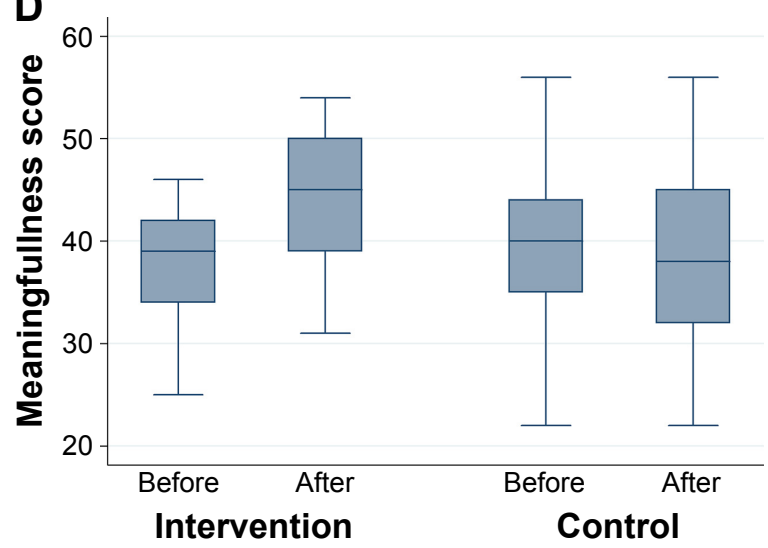

Figure 3 Box plot diagram of the mean score of SOC and its dimensions (comprehensibility, manageability, and meaningfulness) before and after the intervention in both groups.

Note: (A) SOC, (B) comprehensibility, (C) manageability, and (D) meaningfulness.

Abbreviation: SOC, sense of coherence.

The seniors were much interested in the study and actively participated in all intervention sessions and follow-up programs. Seemingly, most of the participants had no special plans for their retirement. On retirement, the majority experienced a sense of lost dignity and reduced social importance. The results showed that the implementation of our intervention was effective on the self-efficacy and SOC of the participants. Moreover, our results showed that an 8-week implementation of the model led to a significant increase in their self-efficacy and SOC by 9 and 24 units, respectively.

As shown in Table 1, there was no statistically significant difference in demographic information between the control and intervention groups. The mean age of the participants in both groups was approximately 63 years, which was classified as young elderly. Such age category could have been the reason for their strong desire and higher motivation to maintain health, dynamic, and activity. Although both groups were similar in terms of sex and education level, we verified the effect of group characteristics on the data. After controlling the possible effect of confounding variables (eg, age, sex, education) and the size of the outcome variable before the intervention, the results were statistically significant. This indicated that the change in the outcome variable in the intervention group was greater than in the control group. Since a difference was found between the older men and the older women on the criteria of receiving social care ${ }^{44}$ further studies on the empowerment of the elderly with an emphasis on sex and important available resources are recommended.

The highest prevalent diseases among the participants were diabetes and high blood pressure, which are the underlying causes of metabolic syndrome. About $83.3 \%$ of the participants had at least two concurrent abnormalities, of whom $23.3 \%$ suffered from a cardiovascular disease. The results were consistent with a cohort study by Ostovar et al ${ }^{45}$ on the elderly in Bushehr, which indicated a high prevalence of cardiovascular diseases and metabolic syndromes. 
The role of face-to-face training and individual interviews is evident in determining the true nature of the problems of the participants and their motivation to participate. In addition, explicit empowerment strategies to identify and adopt adaptation and self-management convey enhanced SOC and self-efficacy. Nguyen et al used two methods (face-to-face and internet training) to show the effect of a self-management program on self-efficacy in older adults with chronic pulmonary failure. Over a 6-month period, significant improvement in self-efficacy through face-to-face training was evident. ${ }^{46}$ Emme et al conducted a study on virtual learning in patients with chronic pulmonary failure at intervals of 3 days, 6 weeks, and 3 months. On completion, no significant difference in self-efficacy was found. ${ }^{47}$ However, they indicated a small sample size as a limitation of their study, which led to undesirable results.

In addition to face-to-face interviews and virtual learning, alternatives such as telephone follow-up and educational booklets can be effective in creating a sense of value, motivation, and adherence to treatment in the elderly. The effectiveness of these alternatives was confirmed by a significant improvement in the SOC and self-efficacy scores. Kaveh Savadkooh et al ${ }^{48}$ conducted an educational intervention in the form of a 1-day training workshop and a 2-month telephone follow-up in elderly patients with high initial hypertension. Behzad et $\mathrm{al}^{49}$ also studied the effect of an empowerment program on self-management in hypertensive patients based on the telephone follow-up. In line with our study, the above-mentioned studies showed a significant improvement in self-efficacy.

In the present study, we attempted to empower the participants through a five-stage plan. We focused on the two psychological fields of self-efficacy and SOC that included different physical, mental, and social aspects. Some studies in the field of empowerment had focused solely on a specific disease or other health aspects. Benz et a ${ }^{50}$ found a significant relationship between the physical and psychological health in patients with knee and hip arthritis. They stated that a strong SOC is appropriate and consistent with the improved health behavior. In contrast, Pakkala et $\mathrm{a}^{51}$ reported that physical activity and exercise did not affect the SOC in patients with pelvic fracture. Note that, as stated, their study did not include enough sample size for an adequate analysis. In addition, the intolerance and subordination of physical activity and exercise training in patients with a previous fracture were the main limitations of the study. Kouvonen et al found a significant relationship between the SOC and diabetes. The reduced SOC was associated with an increased risk of diabetes. They found a direct relationship between low SOC and physiologically effective consequences on health. ${ }^{52}$ In all the above-mentioned studies, lack of attention to all aspects of physical and mental health, the use of different criteria in assessing the effectiveness of empowerment programs, and programs with or without a specific structure led to inconsistent findings.

Musavinasab et al studied the effect of an empowering self-management model on the SOC in elderly patients with cardiovascular diseases. They reported a statistically significant difference in the SOC scores. Subsequently, they introduced this model as a framework for nursing education. ${ }^{38}$ In their study, a systematic structure and a specific empowering self-management model were used with a specific educational schedule, appropriate assessment criteria, telephone follow-up during the intervention, and the provision of a booklet for consolidation of materials. However, they solely focused on cardiovascular diseases and did not consider other diseases and issues associated with the aging period. In contrast, we included several chronic diseases with common risk factors among the retired elderly people.

Based on the results of the present study, the SOC score was increased in all three dimensions (comprehensibility, manageability, and meaningfulness). The implemented intervention improved the manageability of events by nine units. This result was expected, since the empowering selfmanagement model, in essence, emphasizes on improved manageability of a person. Consistent with our study, Musavinasab et al considered the use of the empowering self-management model as efficient in cardiovascular patients and effective in improving the SOC, especially the dimension of manageability. ${ }^{38}$

\section{Strengths and limitations}

The main strength of the present study was the use of an empowering self-management model. The content of the intervention was determined based on a literature review and the findings of a qualitative study that enhanced the perception of "power" among a sample of Iranian older adults. In addition, we applied a homogenize intervention by using an algorithm that was developed based on the expert opinions of nurses and public health care professionals, which included a set of specific objectives and goals.

The present study also had some limitations. First, the study population was based on convenient sampling, and the sample size was relatively small and limited to a single health care center. Therefore, the findings of the study cannot be generalized as it lacks the impact of regional differences 
and cultural factors. Second, the effect of the intervention could be dependent on the cultural framework, which was not considered. Third, considering the resources available to the elderly, family, and the environment are the most important factors in solving their problems. Moreover, the extent of the empowerment can vary between women and men. Hence, it is recommended to conduct more advanced studies that include these factors. Finally, we did not follow-up the participants beyond 2 months. Therefore, the long-term effect of the improvements cannot be judged.

\section{Conclusion}

The main goals of the study were achieved by applying an empowering self-management model. Empowerment was achieved in various aspects of the life of the elderly, including self-awareness of changes, improvement in autonomy, adaptation, a higher sense of control, and life satisfaction. By creating an awareness of their living, environmental, and social conditions, as well as of the available resources, we managed to motivate the elderly to clearly identify their management abilities toward self-reliance and problem solving.

Considering the importance of empowerment, further study is required on a larger sample size, broader age range, and other problems of the elderly. Nursing communities, as community-oriented nurses, should apply such models in the therapeutic or nontherapeutic environment to promote better living standards for the elderly.

\section{Data sharing statement}

Study protocol, statistical analysis plan, and analytic code, as well as individual participant data (after de-identification), that underlie the results reported in this article will be available immediately after publication for researchers who provide a methodologically sound proposal. Proposals should be directed to ravanipour@gmail.com, and to gain access, data requestors will need to sign a data access agreement.

\section{Acknowledgments}

The present manuscript was extracted from the Master's thesis by Azam Hourzad, Faculty of Nursing and Midwifery of Bushehr University of Medical Sciences, Bushehr, Iran. The study was approved by the Research Council (grant number: 5436) and the Research Ethics Committee (code: ir.bpums.rec.2015.134) of Bushehr University of Medical Sciences, Bushehr, Iran. The study protocol was registered at the Iranian Registry of Clinical Trials (registration number: IRCT2015090513092N9). We would like to thank the Deputy of Research at Bushehr University of Medical Sciences for the financial support. We would like to express our gratitude to the local authorities for their support and the participants and families for their active participation in the study. The contribution by the Director and staff of "The Persian Gulf Tropical Medicine Research Center" is very much appreciated.

\section{Disclosure}

The authors report no conflicts of interest in this work.

\section{References}

1. Ahmadi B, Alimohammadian M, Yaseri M, et al. Multimorbidity: Epidemiology and Risk Factors in the Golestan Cohort Study, Iran: A Cross-Sectional Analysis. Medicine. 2016;95(7):e2756.

2. Eliopoulos C. Gerontological Nursing. Philadelphia, PA: Lippincott Williams \& Wilkins; 2013.

3. Teymoori F, Dadkhah A, Shirazikhah M. Social welfare and health (mental, social, physical) status of aged people in Iran. Middle East $J$ Age Ageing. 2006;3(1):39-45.

4. Noroozian M. The elderly population in Iran: an ever growing concern in the health system. Iran J Psychiatry Behav Sci. 2012;6(2):1.

5. Amini R, Ingman SR, Sahaf R. Aging in Iran: past, present and future J Aging Emerg Econ. 2013;4(1):17-34.

6. Wilson DM, Palha P. A systematic review of published research articles on health promotion at retirement. J Nurs Scholarsh. 2007;39(4): 330-337.

7. Söderhamn O, Skisland A, Herrman M. Self-care and anticipated transition into retirement and later life in a Nordic welfare context. J Multidiscip Healthc. 2011;4(1):273-279.

8. Plawecki HM, Plawecki LH. Challenges of Retirement. J Gerontol Nurs. 2016;42(11):3-5.

9. Chen IH, Chi MJ. Effects of self-care behaviors on medical utilization of the elderly with chronic diseases - A representative sample study. Arch Gerontol Geriatr. 2015;60(3):478-485.

10. Macleod S, Musich S, Hawkins K, Alsgaard K, Wicker ER. The impact of resilience among older adults. Geriatr Nurs. 2016;37(4):266-272.

11. Aujoulat I, Marcolongo R, Bonadiman L, Deccache A. Reconsidering patient empowerment in chronic illness: a critique of models of selfefficacy and bodily control. Soc Sci Med. 2008;66(5):1228-1239.

12. Ravanipour M, Salehi S, Taleghani F, et al. Power resources of older people in Iran. Int J Older People Nurs. 2013;8(1):71-79.

13. Bandura A, Adams NE. Analysis of self-efficacy theory of behavioral change. Cognitive Therapy and Research. 1977;1(4):287-310.

14. Schwarzer R. Self-Efficacy: Thought Control of Action. New York: Taylor \& Francis; 2014.

15. de Vries H. Self-efficacy: skip the main factor paradigm! A comment on Williams and Rhodes (2016). Health Psychol Rev. 2016;10(2): 140-143.

16. Cybulski M, Cybulski L, Krajewska-Kulak E, Cwalina U. The level of emotion control, anxiety, and self-efficacy in the elderly in Bialystok, Poland. Clin Interv Aging. 2017;12:305-314.

17. Khobbin khoshnazar Tas, Izadi-Tameh A, Moghadamnia MT, et al. Relevance self-efficacy with anxiety and depression among patients receiving hemodialysis referred to hemodialysis unit at educationaltherapeutic center in Rasht. J Urmia Nurs Midwifery Faculty. 2014; 12(9):807-814.

18. Morowatisharifabad M, Tonekaboni NR. Perceived self-efficacy in self-care behaviors among diabetic patients referring to Yazd Diabetes Research Center. J Birjand Univ Med Sci. 2008;15(4):91-99.

19. Antonovsky A. The structure and properties of the sense of coherence scale. Soc Sci Med. 1993;36(6):725-733. 
20. Bengtsson-Tops A, Hansson L. The validity of Antonovsky's Sense of Coherence measure in a sample of schizophrenic patients living in the community. J Adv Nurs. 2001;33(4):432-438.

21. Hobkirk AB. The relationships between leadership styles and sense of coherence, self efficacy and locus of control in a utility organization. Mini-dissertation submitted in partial fulfilment of the requirements for the degree Magister; Artium in Industrial Psychology in the School of Behavioural Sciences at the Potchefstroom, University for Christian Higher Education. 2003.

22. Seah B, Kowitlawakul Y, Chokkanathan S, et al. Salutogenic Healthy Ageing Programme Embracement (SHAPE) for senior-only households: A study protocol. J Adv Nurs. 2018;74(4):946-956.

23. Holmberg S, Thelin A, Stiernström E-L. Relationship of Sense of Coherence to Other Psychosocial Indices. Eur J Psychol Assess. 2004; 20(4):227-236.

24. Fotoukian Z, Shahboulaghi FM, Khoshknab MF, Mohammadi E. Concept analysis of empowerment in old people with chronic diseases using a hybrid model. Asian Nurs Res. 2014;8(2):118-127.

25. Fok SK, Chair SY, Lopez V, Coherence Sof. Sense of coherence, coping and quality of life following a critical illness. J Adv Nurs. 2005;49(2): $173-181$.

26. Hart KE, Wilson TL, Hittner JB. A psychosocial resilience model to account for medical well-being in relation to sense of coherence. J Health Psychol. 2006;11(6):857-862.

27. Kröninger-Jungaberle H, Grevenstein D. Development of salutogenetic factors in mental health - Antonovsky's sense of coherence and Bandura's self-efficacy related to Derogatis' symptom check list (SCL90-R). Health Qual Life Outcomes. 2013;11(1):80.

28. Posadzki P, Glass N. Self-efficacy and the sense of coherence: narrative review and a conceptual synthesis. Sci World J. 2009;9:924-933.

29. Koelen MA, Lindström B. Making healthy choices easy choices: the role of empowerment. Eur J Clin Nutr. 2005;59(Suppl 1):S10-S16.

30. Leidy NK, Haase JE. Functional status from the patient's perspective: the challenge of preserving personal integrity. Res Nurs Health. 1999;22(1):67-77.

31. Shearer N, Fleury J. Social support promoting health in older women. $J$ Women Aging. 2006;18(4):3-17.

32. Lewin D, Piper S. Patient empowerment within a coronary care unit: insights for health professionals drawn from a patient satisfaction survey. Intensive Crit Care Nurs. 2007;23(2):81-90.

33. Ravanipour M, Salehi S, Taleghani F, Abedi HA, Schuurmans MJ, Jong ADE. Sense of power among older people in Iran. Educ Gerontol. 2008;34(10):923-938.

34. Fazekas C, Semlitsch B, Pieringer W. Empowerment in diabetes mellitus: theory and practice. Wien Med Wochenschr. 2003;153(21-22): 459-463.

35. Meetoo D, Gopaul H. Empowerment: giving power to people with diabetes. J Diabetes Nurs. 2005;9(1):28-32.

36. Samavat T, Hojatzadeh A. Programs of prevention and control cardiovascular diseases. Iranian Ministry of Health and Medical Education; 2012. Available from: http://phc.umsu.ac.ir/uploads/ pishgiri-htn.pdf. Accessed October 18, 2018.

37. Vahedparast H, Mohammadi E, Ahmadi F. From threat to gradual lifestyle changes: Iranians' experiences with chronic illnesses. Int Nurs Rev. 2017;64(3):405-412.
38. Musavinasab M, Ravanipour M, Pouladi S, Motamed N, Barekat M. The effect of self-management empowerment model on the sense of coherence among elderly patients with cardiovascular disease. Educ Gerontol. 2016;42(2):100-108.

39. Ravanipour M, Salehi S, Taleghani F, et al. Power in Iranian elders: Barriers and facilitators. Psychogeriatria Polska. 2008;5(3):114-121.

40. Sherer M, Maddux JE, Mercandante B, Prentice-Dunn S, Jacobs B, Rogers RW. The Self-Efficacy Scale: Construction and Validation. Psychol Rep. 1982;51(2):663-671.

41. Khodarahimi S. General self-efficacy and worry in an Iranian adolescents and youths samples. Educ Res. 2010;1(2):15-20.

42. Jahanimaleki S, Sharifi M, Jahanimaleki R, Nazari G. The Relationship between Awareness Levels of Life Skill with Self Efficacy Beliefs among Shahid Beheshti University Student. J Modern Psycholo Res. 2011;6(22):19-49.

43. Alipour A, Sharif N. Validity and reliability of the Sense of Coherence (SOC) questionnaire in university students. Pajoohandeh J. 2012; 17(1):50-56.

44. Vlachantoni A, Shaw RJ, Evandrou M, Falkingham J. The determinants of receiving social care in later life in England. Ageing Soc. 2015; 35(2):321-345.

45. Ostovar A, Nabipour I, Larijani B, et al. Bushehr Elderly Health (BEH) Programme, phase I (cardiovascular system). BMJ Open. 2015; 5(12):e009597.

46. Nguyen HQ, Donesky-Cuenco D, Wolpin S, et al. Randomized controlled trial of an internet-based versus face-to-face dyspnea selfmanagement program for patients with chronic obstructive pulmonary disease: pilot study. J Med Internet Res. 2008;10(2):e9.

47. Emme C, Mortensen EL, Rydahl-Hansen S, et al. The impact of virtual admission on self-efficacy in patients with chronic obstructive pulmonary disease - a randomised clinical trial. J Clin Nurs. 2014; 23(21-22):3124-3137.

48. Kaveh Savadkooh O, Zakerimoghadam M, Gheyasvandian S. Effect of self-management program on self-efficacy in hypertensive patients. J Mazandaran Univ Med Sci. 2012;22(92):19-28.

49. Behzad Y, Bastani F, Haghani H. Effect of empowerment program with the telephon follow-up (Tele-Nursing) on self-efficacy in self-care behaviors in hypertensive older adult. J Urmia Nurs Midwif Facul. 2016;13(11):1004-1015.

50. Benz T, Angst F, Lehmann S, Aeschlimann A. Association of the sense of coherence with physical and psychosocial health in the rehabilitation of osteoarthritis of the hip and knee: a prospective cohort study. $B M C$ Musculoskelet Disord. 2013;14(1):159.

51. Pakkala I, Read S, Sipilä S, et al. Effects of intensive strength-power training on sense of coherence among 60-85-year-old people with hip fracture: a randomized controlled trial. Aging Clin Exp Res. 2012; 24(3):295-299.

52. Kouvonen AM, Väänänen A, Woods SA, Heponiemi T, Koskinen A, Toppinen-Tanner S. Sense of coherence and diabetes: a prospective occupational cohort study. BMC Public Health. 2008;8(1):46.
Clinical Interventions in Aging

\section{Publish your work in this journal}

Clinical Interventions in Aging is an international, peer-reviewed journal focusing on evidence-based reports on the value or lack thereof of treatments intended to prevent or delay the onset of maladaptive correlates of aging in human beings. This journal is indexed on PubMed Central, MedLine,

\section{Dovepress}

CAS, Scopus and the Elsevier Bibliographic databases. The manuscript management system is completely online and includes a very quick and fair peer-review system, which is all easy to use. Visit http://www.dovepress. $\mathrm{com} /$ testimonials.php to read real quotes from published authors. 